\title{
DIMENSI PARTISI PADA GRAF
}

\author{
Annisatul Khairiah, Evi Noviani, Fransiskus Fran
}

\section{INTISARI}

Diberikan sebuah graf terhubung $G=(V, E)$. Simpul $V$ dikelompokkan ke dalam $k$-partisi yaitu $\Pi=$ $\left\{S_{1}, S_{2}, \ldots, S_{k}\right\}$ dengan $S_{i} \subseteq V(G)$. Representasi dari $v$ terhadap $\Pi$ yaitu $\vec{r}(v \mid \Pi)=\left(d\left(v, S_{1}\right), d\left(v, S_{2}\right)\right.$, $\left.\ldots, d\left(v, S_{k}\right)\right)$ dengan $d(v, S)=\min \{d(v, x) \mid x \in S\}$ dan $v$ merupakan simpul di $G$. Jika representasi yang dihasilkan memiliki vektor koordinat yang berbeda, maka П merupakan partisi pembeda dari graf G. Apabila $k$ merupakan nilai minimum dari banyaknya partisi di П, maka $k$ merupakan dimensi partisi dari graf $G$, dinotasikan dengan $p d(G)=k$. Pada penelitian ini dibahas cara menentukan formula dimensi partisi pada graf sisir, graf garis dan graf kuadrat dari graf sisir. Graf sisir adalah graf yang diperoleh dari hasil operasi korona antara graf lintasan $P_{n}$ dengan graf lengkap $K_{1}$. Graf sisir $\left(C b_{n}\right)$ memiliki $2 n$ simpul dan $2 n-1$ sisi. Graf garis dari graf sisir $\left(L\left(C b_{n}\right)\right)$ adalah graf yang memiliki jumlah simpul sama dengan jumlah sisi dari graf $C b_{n}$. Simpul pada graf garis tersebut akan bertetangga jika dan hanya jika sisi-sisi yang bersesuaian saling terhubung pada graf $C b_{n}$. Graf kuadrat dari graf sisir $\left(C b_{n}^{2}\right)$ yaitu sebuah graf yang memiliki jumlah simpul yang sama dengan simpul pada graf $C b_{n}$, dengan menambahkan sisi pada dua simpul yang berjarak dua. Hasil dari penelitian ini diperoleh dimensi partisi dari graf sisir yaitu 2 , untuk $n=2$ dan 3 , untuk $n \geq 3$. Dimensi partisi pada graf garis dari graf sisir yaitu 2 , untuk $n=2$ dan 3 , untuk $n \geq 3$ serta dimensi partisi pada graf kuadrat dari graf sisir yaitu 3, untuk $n=2$ dan $n=3,4$, untuk $n \geq 4$.

Kata Kunci: Partisi pembeda, graf sisir, graf garis, graf kuadrat.

\section{PENDAHULUAN}

Teori graf merupakan bagian dari matematika diskrit yang digunakan untuk merepresentasikan suatu objek dan hubungan antara objek-objek tersebut. Objek pada graf dinyatakan dengan bulatan maupun titik, sedangkan hubungan antara objek-objek tersebut dinyatakan dengan garis. Teori graf bermanfaat dalam kehidupan sehari-hari yaitu pada transportasi, jaringan komunikasi, dan peta.

Penelitian tentang graf sangat menarik karena banyak memiliki terapan. Topik yang sering dibahas pada teori graf diantaranya tentang pelabelan, pewarnaan, bilangan kromatik, dimensi metrik, dan dimensi partisi. Dimensi partisi diperkenalkan pertama kali oleh Chartrand dkk pada tahun 1998. Dimensi partisi diperoleh dengan cara mengelompokkan semua simpul pada graf $G$ ke dalam sejumlah kelas partisi. Selanjutnya menentukan jarak seluruh simpul terhadap setiap kelas partisi untuk mendapatkan representasi. Representasi yang memiliki vektor koordinat berbeda dan memiliki jumlah kardinalitas minimum merupakan dimensi partisi dari graf $G$.

Adapun contoh penerapan dari dimensi partisi ini yaitu navigasi robot [1]. Pada navigasi robot, robot ini bergerak dari satu titik lokasi ke titik yang lain berdasarkan kode yang telah diperoleh. Kode tersebut diterjemahkan harus dengan tingkat kesalahan yang sedikit agar robot bisa sampai ke tujuan dengan tepat. Oleh karena itu, setiap titik lokasi harus diberikan kode yang berbeda. Misalkan titik lokasi dianggap sebagai simpul dan lintasan robot dianggap sebagai sisi, maka bidang gerak robot bisa direpresentasikan sebagai sebuah graf. Penelitian ini dibahas tentang dimensi partisi dari beberapa graf yaitu graf sisir, graf garis dan graf kuadrat dari graf sisir. Graf sisir adalah graf yang diperoleh dari hasil operasi korona antara graf lintasan $P_{n}$ dengan graf lengkap $K_{1}$. Sedangkan graf garis adalah graf yang memilki jumlah simpul sama dengan jumlah sisi pada graf $G$, namun simpul pada graf garis tersebut akan bertetangga jika dan haya jika sisi yang bersesuaian saling terhubung pada graf $G$. Graf 
kuadrat adalah graf yang memiliki jumlah simpul yang sama dengan simpul pada graf $G$, dengan menambahkan sisi baru di antara setiap dua simpul yang berjarak dua dalam graf $G$.

\section{DIMENSI PARTISI}

Graf $G$ didefinisikan sebagai pasangan himpunan $(V, E)$, ditulis dengan notasi $G=(V, E)$, yang dalam hal ini $V$ adalah himpunan tidak kosong dari simpul-simpul (vertices atau node) dan $E$ adalah himpunan sisi (edges atau arc) yang menghubungkan sepasang simpul [2]. Adapun graf yang dibahas yaitu graf yang berkaitan dengan graf lintasan dan graf lengkap.

Graf lintasan adalah graf sederhana yang kedua simpul ujung berderajat satu, sedangkan simpul yang lain berderajat dua. Graf lintasan dinotasikan dengan $P_{n}$ [3]. Adapun contoh dari graf lintasan terdapat pada Gambar 1 (a). Graf lengkap adalah graf sederhana yang setiap simpulnya memilki sisi yang terhubung ke simpul lainnya. Graf lengkap dengan $n$ buah simpul dilambangkan dengan $K_{n}$. Jumlah sisi pada graf lengkap yang terdiri dari $n$ buah simpul adalah $n(n-1) / 2$ [2]. Adapun contoh dari graf lengkap terdapat pada Gambar 1 (b). Misalkan $P_{n}$ menjadi graf lintasan dengan $n$ simpul. Graf sisir $C b_{n}$ didefinisikan sebagai $P_{n} \odot K_{1}$ yang memiliki $2 n$ simpul dan $2 n-1$ sisi [4]. Adapun contoh dari graf sisir terdapat pada Gambar 1 (c). Misal graf $G$ dengan himpunan simpul $V(G)$ dan himpunan sisi $E(G)$. Graf garis (line graph) $L(G)$ adalah graf dengan $V(L(G))=E(G)$ dan simpul di $L(G)$ akan bertetangga jika dan hanya jika sisi-sisi yang bersesuaian terhubung di $G$ [5]. Adapun contoh graf garis dari graf sisir terdapat pada Gambar 1 (d). Kuadrat $G^{2}$ dari graf $G$ yang diperoleh dari graf $G$ dengan menambahkan sisi baru di antara setiap dua simpul yang memiliki jarak dua dalam graf $G$ [6]. Adapun contoh graf kuadrat dari graf sisir terdapat pada Gambar 1 (e).

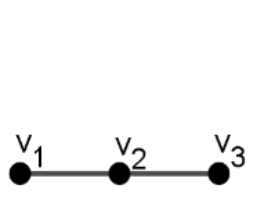

(a)

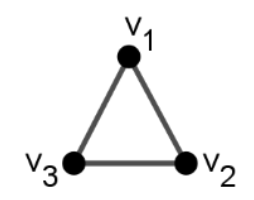

(b)

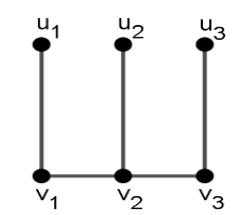

(c)

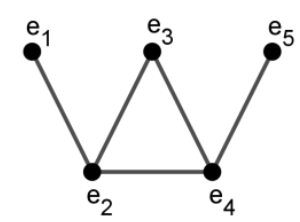

(d)

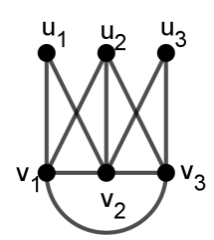

(e)

Gambar 1 (a) Graf lintasan $P_{3}$, (b) graf lengkap $K_{3}$, (c) graf sisir $C b_{3}$, (d) graf garis $L\left(C b_{4}\right)$,

(e) graf kuadrat $C b_{n}^{2}$

Dimensi partisi diperoleh dengan cara mengelompokkan semua simpul di $G$ ke dalam sejumlah kelas partisi. Selanjutnya menentukan jarak setiap simpul terhadap setiap kelas partisi untuk mendapatkan representasi. Jika representasi setiap simpul terhadap $\Pi$ berbeda, maka $\Pi$ merupakan partisi pembeda. Kemudian kardinalitas minimum dari banyaknya partisi disebut dimensi partisi. Berikut diberikan definisi partisi secara umum dan definisi dimensi partisi.

Definisi 1 [2] Partisi dari sebuah himpunan A adalah sekumpulan himpunan bagian tidak kosong $A_{1}, A_{2}, \ldots$ dari $A$ sedemikian sehingga:

(a) $A_{1} \cup A_{2} \cup \ldots=A$, dan

(b) Himpunan bagian $A_{i}$ saling lepas, yaitu $A_{i} \cap A_{j}=\emptyset$ untuk $i \neq j$.

Definisi 2 [7] Misalkan $G$ adalah suatu graf terhubung dengan himpunan simpul $V(G)$ yang dipartisi menjadi beberapa partisi, misal $S_{1}, S_{2}, \ldots, S_{k}$. Notasikan $\Pi$ sebagai suatu himpunan terurut dari $k$ partisi, tulis $\Pi=\left\{S_{1}, S_{2}, \ldots, S_{k}\right\}$. Misalkan terdapat suatu simpul $v$ di $G$, maka representasi $v$ 
terhadap $\Pi$ didefinisikan sebagai jarak dari $v$ ke tiap-tiap partisi $d i \quad \Pi$, ditulis $\vec{r}(v \mid \Pi)=\left(d\left(v, S_{1}\right), d\left(v, S_{2}\right), \ldots, d\left(v, S_{k}\right)\right)$. Selanjutnya $\vec{r}(v \mid \Pi)$ disebut sebagai vektor penyajian. Jika setiap simpul yang berbeda di $G$ mempunyai representasi yang berbeda terhadap $\Pi$, maka $\Pi$ disebut sebagai partisi pembeda. Kardinalitas minimum dari k-partisi pembeda terhadap $V(G)$ disebut dimensi partisi dari $G$, dinotasikan dengan $p d(G)$.

Dalam penelitian [8], terdapat beberapa hasil dimensi partisi dari berbagai jenis graf. Salah satunya dimensi partisi pada graf $G$ yaitu $p d(G)=2$ jika dan hanya jika $G$ merupakan graf lintasan $\left(P_{n}\right)$.

Proposisi 3 [8] Misalkan $G$ suatu graf terhubung. Dimensi partisi graf $G$ yaitu $p d(G)=2$ jika dan hanya jika $G=P_{n}$, dengan $n \geq 2$.

Contoh 4 Misalkan diberikan sebuah graf lengkap $K_{4}$ pada Gambar 2, selanjutnya akan ditentukan dimensi partisi dari graf $K_{4}$ tersebut:

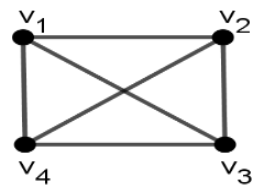

Gambar 2 Graf $K_{4}$

Berdasarkan Gambar 2, graf $K_{4}$ akan dipartisi menjadi empat bagian. Pilih $\Pi=\left\{S_{1}, S_{2}, S_{3}, S_{4}\right\}$ dengan $S_{1}=\left\{v_{1}\right\}, S_{2}=\left\{v_{2}\right\}, S_{3}=\left\{v_{3}\right\}$, dan $S_{4}=\left\{v_{4}\right\}$. Oleh karena itu diperoleh representasi setiap simpul terhadap $\Pi$ pada graf $K_{4}$ yaitu:

$$
\begin{array}{ll}
\vec{r}\left(v_{1} \mid \Pi\right)=(0,1,1,1) & \vec{r}\left(v_{3} \mid \Pi\right)=(1,1,0,1) \\
\vec{r}\left(v_{2} \mid \Pi\right)=(1,0,1,1) & \vec{r}\left(v_{4} \mid \Pi\right)=(1,1,1,0) .
\end{array}
$$

Oleh karena representasi setiap simpul terhadap $\Pi=\left\{S_{1}, S_{2}, S_{3}, S_{4}\right\}$ memiliki vektor koordinat yang berbeda, maka $\Pi$ merupakan partisi pembeda dari semua simpul di $K_{4}$. Selanjutnya $\Pi=$ $\left\{S_{1}, S_{2}, S_{3}, S_{4}\right\}$ memiliki jumlah anggota minimum yaitu empat. Dengan demikian, dapat disimpulkan bahwa $p d\left(K_{4}\right)=4$.

Selanjutnya dimensi partisi pada graf sisir, graf garis dan graf kuadrat dari graf sisir akan dijelaskan pada proposisi-proposisi berikut.

Proposisi $5 \mathrm{Jika} \mathrm{Cb}_{n}$ adalah graf sisir dengan $n \in \mathbb{N}$, maka:

$$
\operatorname{pd}\left(C b_{n}\right)=\left\{\begin{array}{l}
2, \text { untuk } n=2 \\
3, \text { untuk } n \geq 3 .
\end{array}\right.
$$

Bukti: Misalkan graf $C b_{n}$ memiliki simpul $\left\{u_{1}, v_{1}, u_{2}, v_{2}, \ldots, u_{n}, v_{n}\right\}$. Berdasarkan Proposisi 5, untuk menunjukkan dimensi partisi pada graf sisir $C b_{n}$ dengan $n$ simpul akan dibagi menjadi dua kasus. Kasus pertama untuk $n=2$ dan untuk kasus kedua $n \geq 3$.

Kasus 1: Untuk $n=2$

Oleh karena bentuk graf $\mathrm{Cb}_{2}$ merupakan bentuk dari graf lintasan $P_{4}$ maka berdasarkan Proposisi 3 , $p d\left(C b_{2}\right)=p d\left(P_{4}\right)=2$.

Kasus 2: Untuk $n \geq 3$

Oleh karena $C b_{n}$ bukan merupakan graf lintasan maka berdasarkan Proposisi 3, $p d\left(C b_{n}\right) \neq 2$. Selanjutnya karena bilangan yang paling minimum setelah 2 yaitu 3 dan dimensi partisi yang bernilai 1 hanya bisa berlaku pada graf khusus, dengan demikian dapat disimpulkan bahwa $p d\left(C b_{n}\right) \geq 3$. Misalkan $\Pi=\left\{S_{1}, S_{2}, S_{3}\right\}$ adalah partisi pembeda dari $C b_{n}$ dengan $S_{1}=\left\{u_{1}\right\}, S_{2}=\left\{v_{1}, \ldots, u_{n-1}\right\}$, dan $S_{3}=\left\{v_{n-1}, u_{n}, v_{n}\right\}$. Akan ditunjukkan bahwa semua simpul $C b_{n}$ memiliki representasi berbeda terhadap П. Representasi semua simpul $C b_{n}$ adalah sebagai berikut:

$$
\begin{array}{ll}
\vec{r}\left(u_{1} \mid \Pi\right) & =(0,1, n-1) \\
\vec{r}\left(v_{1} \mid \Pi\right) & =(0,1, n-2)
\end{array}
$$




$$
\begin{aligned}
& \vec{r}\left(u_{n-1} \mid \Pi\right)=(n, 0,1) \\
& \vec{r}\left(v_{n-1} \mid \Pi\right)=(n-1,1,0) \\
& \vec{r}\left(u_{n} \mid \Pi\right)=(n+1,3,0) \\
& \vec{r}\left(v_{n} \mid \Pi\right)=(n, 2,0) .
\end{aligned}
$$

Oleh karena semua simpul $C b_{n}$ memiliki representasi yang berbeda, maka $\Pi=\left\{S_{1}, S_{2}, S_{3}\right\}$ adalah partisi pembeda dari $C b_{n}$. Akibatnya $p d\left(C b_{n}\right) \leq 3$. Oleh karena $p d\left(C b_{n}\right) \geq 3$ dan $p d\left(C b_{n}\right) \leq 3$, maka terbukti bahwa $p d\left(C b_{n}\right)=3$.

Proposisi 6 Jika $L\left(C b_{n}\right)$ adalah graf garis dari graf sisir dengan $n \in \mathbb{N}$, maka:

$$
\operatorname{pd}\left(L\left(C b_{n}\right)\right)=\left\{\begin{array}{l}
2, \text { untuk } n=2 \\
3, \text { untuk } n \geq 3
\end{array}\right.
$$

Bukti: Misalkan graf $L\left(C b_{n}\right)$ memiliki simpul $\left\{e_{1}, e_{2}, e_{3}, \ldots, e_{n}\right\}$. Berdasarkan Proposisi 6, untuk menunjukkan dimensi partisi pada graf $L\left(C b_{n}\right)$ dengan $n$ simpul akan dibagi menjadi dua kasus. Kasus pertama untuk $n=2$ dan untuk kasus kedua $n \geq 3$.

Kasus 1: Untuk $n=2$

Karena bentuk graf $L\left(C b_{2}\right)$ merupakan bentuk dari graf lintasan $P_{3}$ maka berdasarkan Proposisi 3, $p d\left(L\left(C b_{2}\right)\right)=p d\left(P_{3}\right)=2$.

Kasus 2: Untuk $n \geq 3$

Oleh karena $L\left(C b_{n}\right)$ bukan merupakan graf lintasan maka berdasarkan Proposisi 3, $p d\left(L\left(C b_{n}\right)\right) \neq$ 2. Selanjutnya karena bilangan yang paling minimum setelah 2 adalah 3 dan dimensi partisi yang bernilai 1 hanya berlaku pada graf khusus, dengan demikian dapat disimpulkan bahwa $\operatorname{pd}\left(L\left(C b_{n}\right)\right) \geq$ 3. Misalkan $\Pi=\left\{S_{1}, S_{2}, S_{3}\right\}$ adalah partisi pembeda dari $L\left(C b_{n}\right)$ dengan $S_{1}=\left\{e_{1}\right\}, S_{2}=$ $\left\{e_{2}, \ldots, e_{m-2}\right\}$, dan $S_{3}=\left\{e_{m-1}, e_{m}\right\}, m=2 n-1$ merupakan banyak simpul pada $L\left(C b_{n}\right)$. Akan ditunjukkan bahwa semua simpul $L\left(C b_{n}\right)$ memiliki representasi berbeda terhadap П. Representasi semua simpul $L\left(C b_{n}\right)$ adalah sebagai berikut:

$$
\begin{array}{cc}
\vec{r}\left(e_{1} \mid \Pi\right) & =(0,1, m-n) \\
\vec{r}\left(e_{2} \mid \Pi\right) & =(1,0, n-2) \\
\quad & \\
\vec{r}\left(e_{m-2} \mid \Pi\right) & =(n-1,0,1) \\
\vec{r}\left(e_{m-1} \mid \Pi\right) & =(n-1,1,0) \\
\vec{r}\left(e_{m} \mid \Pi\right) & =(n, 2,0) .
\end{array}
$$

Oleh karena semua simpul $L\left(C b_{n}\right)$ memiliki representasi yang berbeda, maka $\Pi=\left\{S_{1}, S_{2}, S_{3}\right\}$ adalah partisi pembeda dari $L\left(C b_{n}\right)$ akibatnya $\operatorname{pd}\left(L\left(C b_{n}\right)\right) \leq 3$. Oleh karena $\operatorname{pd}\left(L\left(C b_{n}\right)\right) \geq 3$ dan $p d\left(L\left(C b_{n}\right)\right) \leq 3$ maka terbukti bahwa $p d\left(L\left(C b_{n}\right)\right)=3$.

Proposisi 7 Jika Cb $b_{n}^{2}$ adalah graf kuadrat dari graf sisir dengan $n \in \mathbb{N}$, maka:

$$
\operatorname{pd}\left(C b_{n}^{2}\right)=\left\{\begin{array}{lll}
3, & \text { untuk } & n=2,3 \\
4, & \text { untuk } & n \geq 4
\end{array}\right.
$$

Bukti: Misalkan graf $C b_{n}^{2}$ memiliki simpul $\left\{u_{1}, v_{1}, u_{2}, v_{2}, \ldots, u_{n}, v_{n}\right\}$. Berdasarkan Proposisi 7, untuk menunjukkan dimensi partisi pada graf $C b_{n}^{2}$ dengan $n$ simpul akan dibagi menjadi tiga kasus. Kasus pertama untuk $n=2$, kasus kedua untuk $n=3$, dan kasus ketiga untuk $n \geq 4$.

Kasus 1: Untuk $n=2$

Oleh karena $C b_{2}^{2}$ bukan merupakan graf lintasan maka berdasarkan Proposisi $3, p d\left(C b_{2}^{2}\right) \neq 3$. Selanjutnya karena bilangan yang paling minimum setelah 2 yaitu 3 dan dimensi partisi yang bernilai 1 hanya bisa berlaku pada graf khusus, dengan demikian dapat disimpulkan bahwa $p d\left(C b_{2}^{2}\right) \geq 3$. Misalkan $\Pi=\left\{S_{1}, S_{2}, S_{3}\right\}$ adalah partisi pembeda dari $C b_{2}^{2}$ dengan $S_{1}=\left\{u_{1}\right\}, S_{2}=\left\{v_{1}, u_{2}\right\}$, dan $S_{3}=\left\{v_{2}\right\}$. Akan ditunjukkan bahwa semua simpul $C b_{2}^{2}$ memiliki representasi berbeda terhadap $\Pi$. Representasi semua simpul $C b_{2}^{2}$ adalah sebagai berikut:

$$
\vec{r}\left(u_{1} \mid \Pi\right)=(0,1,1) \quad \vec{r}\left(v_{1} \mid \Pi\right)=(1,0,1) \quad \vec{r}\left(u_{2} \mid \Pi\right)=(2,0,1) \quad \vec{r}\left(v_{2} \mid \Pi\right)=(1,1,0) .
$$


Oleh karena semua simpul $C b_{2}^{2}$ memiliki representasi yang berbeda, maka $\Pi=\left\{S_{1}, S_{2}, S_{3}\right\}$ adalah partisi pembeda dari $C b_{2}^{2}$. sehingga $p d\left(C b_{2}^{2}\right) \leq 3$. Oleh karena $p d\left(C b_{2}^{2}\right) \geq 3$ dan $p d\left(C b_{2}^{2}\right) \leq 3$ maka terbukti bahwa $p d\left(C b_{2}^{2}\right)=3$.

Kasus 2: Untuk $n=3$

Oleh karena $\mathrm{Cb}_{3}^{2}$ bukan merupakan graf lintasan maka berdasarkan Proposisi 3, $p d\left(C b_{3}^{2}\right) \neq 3$. Selanjutnya karena bilangan yang paling minimum setelah 2 yaitu 3 dan dimensi partisi yang bernilai 1 hanya bisa berlaku pada graf khusus, dengan demikian dapat disimpulkan bahwa $\operatorname{pd}\left(C b_{3}^{2}\right) \geq 3$. Misalkan $\Pi=\left\{S_{1}, S_{2}, S_{3}\right\}$ adalah partisi pembeda dari $C b_{3}^{2}$ dengan $S_{1}=\left\{u_{1}\right\}, S_{2}=\left\{v_{1}, u_{2}\right\}$, dan $S_{3}=\left\{v_{2}, u_{3}, v_{3}\right\}$. Akan ditunjukkan bahwa semua simpul $C b_{3}^{2}$ memiliki representasi berbeda terhadap П. Representasi semua simpul $C b_{3}^{2}$ adalah sebagai berikut:

$$
\begin{array}{lll}
\vec{r}\left(u_{1} \mid \Pi\right)=(0,1,1) & \vec{r}\left(u_{2} \mid \Pi\right)=(2,0,1) & \vec{r}\left(u_{3} \mid \Pi\right)=(2,2,0) \\
\vec{r}\left(v_{1} \mid \Pi\right)=(1,0,1) & \vec{r}\left(v_{2} \mid \Pi\right)=(1,1,0) & \vec{r}\left(v_{3} \mid \Pi\right)=(2,1,0) .
\end{array}
$$

Oleh karena semua simpul $C b_{3}^{2}$ memiliki representasi yang berbeda, maka $\Pi=\left\{S_{1}, S_{2}, S_{3}\right\}$ adalah partisi pembeda dari $C b_{3}^{2}$. Sehingga $p d\left(C b_{3}^{2}\right) \leq 3$. Oleh karena $p d\left(C b_{3}^{2}\right) \geq 3$ dan $p d\left(C b_{3}^{2}\right) \leq 3$ maka terbukti bahwa $p d\left(C b_{3}^{2}\right)=3$.

Kasus 3: Untuk $n \geq 4$

Oleh karena $C b_{n}^{2}$ bukan merupakan graf lintasan maka berdasarkan Proposisi 3, $p d\left(C b_{n}^{2}\right) \neq 3$. Selanjutnya karena bilangan yang paling minimum setelah 2 yaitu 3 dan dimensi partisi yang bernilai 1 hanya bisa berlaku pada graf khusus, dengan demikian dapat disimpulkan bahwa $p d\left(C b_{n}^{2}\right) \geq 3$. Selanjutnya akan ditunjukkan $p d\left(C b_{n}^{2}\right) \leq 4$. Misalkan $\Pi=\left\{S_{1}, S_{2}, S_{3}, S_{4}\right\}$ adalah partisi pembeda dari $C b_{n}^{2}$ dengan $S_{1}=\left\{u_{1}\right\}, S_{2}=\left\{v_{1}, u_{2}\right\}, S_{3}=\left\{v_{2}, \ldots, u_{n-1}\right\}$ dan $S_{4}=\left\{v_{n-1}, u_{n}, v_{n}\right\}$. Akan ditunjukkan bahwa semua simpul $C b_{n}^{2}$ memiliki representasi berbeda terhadap П. Representasi semua simpul $C b_{n}^{2}$ adalah sebagai berikut:

untuk representasi semua simpul $u_{n}$ terhadap partisi П yaitu,

$$
\begin{aligned}
\vec{r}\left(u_{1} \mid \Pi\right) & =\left(0,1,1,\left\lfloor\frac{n}{2}\right\rfloor\right) \\
\vec{r}\left(u_{2} \mid \Pi\right) & \left.=\left(2,0,1, \mid \frac{n}{2}\right\rceil-1\right) \\
\vdots & \\
\vec{r}\left(u_{n-2} \mid \Pi\right) & =\left(\left\lfloor\frac{n}{2}\right\rfloor,\left\lceil\frac{n}{2}\right\rceil-1,0,1\right) \\
\vec{r}\left(u_{n-1} \mid \Pi\right) & =\left(\left\lceil\frac{n}{2}\right\rceil,\left\lfloor\frac{n}{2}\right\rfloor 0,1\right) \\
\vec{r}\left(u_{n} \mid \Pi\right) & =\left(\left\lfloor\frac{n}{2}\right\rfloor+1,\left\lceil\frac{n}{2}\right\rceil 2,0\right)
\end{aligned}
$$

untuk representasi semua simpul $v_{n}$ terhadap partisi $\Pi$ yaitu,

$$
\begin{aligned}
\vec{r}\left(v_{1} \mid \Pi\right) & =\left(1,0,1,\left\lceil\frac{n}{2}\right\rceil-1\right) \\
\vec{r}\left(v_{2} \mid \Pi\right) & \left.=\left(1,1,0, \mid \frac{n}{2}\right\rfloor-1\right) \\
\vdots & \vec{r}\left(v_{n-2} \mid \Pi\right)=\left(\left\lceil\frac{n}{2}\right\rceil-1,\left\lfloor\frac{n}{2}\right\rfloor-1,0,1\right) \\
\vec{r}\left(v_{n-1} \mid \Pi\right) & =\left(\left\lfloor\frac{n}{2}\right\rfloor,\left\lceil\frac{n}{2}\right\rceil-1,1,0\right) \\
\vec{r}\left(v_{n} \mid \Pi\right) & =\left(\left[\frac{n}{2}\right\rfloor,\left\lfloor\frac{n}{2}\right\rfloor, 1,0\right) .
\end{aligned}
$$

Oleh karena semua simpul $C b_{n}^{2}$ memiliki representasi yang berbeda, maka $\Pi=\left\{S_{1}, S_{2}, S_{3}, S_{4}\right\}$ adalah partisi pembeda dari $C b_{n}^{2}$ akibatnya $p d\left(C b_{n}^{2}\right) \leq 4$. Selanjutnya akan ditunjukkan bahwa partisi pembeda dari $C b_{n}^{2}$ memiliki kardinalitas kurang dari 4, katakan 3. Tanpa mengurangi keumuman, 
misalkan $\Pi=\left\{S_{1}, S_{2}, S_{3}\right\}$ menjadi partisi dari $C b_{n}^{2}$ dengan $S_{1}=\left\{u_{1}\right\}, S_{2}=\left\{v_{1}, u_{2}, \ldots, u_{n-3}, v_{n-3}\right.$, $\left.u_{n-2}, v_{n-2}, u_{n-1}\right\}$, dan $S_{3}=\left\{v_{n-1}, u_{n}, v_{n}\right\}$. Untuk graf $C b_{n}^{2}$ dengan $n$ ganjil, menghasilkan representasi yang sama yaitu $\vec{r}\left(u_{i} \mid \Pi\right)=\vec{r}\left(v_{i} \mid \Pi\right)$ untuk $i$ ganjil dengan $i=3,5,7, \ldots, n-2$. Sedangkan untuk graf $C b_{n}^{2}$ dengan $n$ genap, menghasilkan representasi yang sama yaitu $\vec{r}\left(u_{i} \mid \Pi\right)=$ $\vec{r}\left(u_{i+1} \mid \Pi\right)$ untuk $i$ genap dengan $2 \leq i \leq n-2$ dan $\vec{r}\left(v_{i} \mid \Pi\right)=\vec{r}\left(v_{i} \mid \Pi\right)$ untuk $i$ ganjil dengan $1 \leq i \leq n-1$. Jadi, $\Pi=\left\{S_{1}, S_{2}, S_{3}\right\}$ bukan merupakan partisi pembeda dari $C b_{n}^{2}$, sehingga $p d\left(C b_{n}^{2}\right) \geq 4$. Akibatnya, $p d\left(C b_{n}^{2}\right)=4$.

\section{KESIMPULAN}

Dimensi partisi pada graf sisir, graf garis dan graf kuadrat dari graf sisir dapat ditentukan dengan cara mengelompokkan semua simpul pada masing-masing graf ke dalam sejumlah kelas partisi. Selanjutnya menentukan jarak setiap simpul terhadap setiap kelas partisi untuk mendapatkan representasi. Jika setiap simpul memiliki representasi yang berbeda terhadap $\Pi$, maka $\Pi$ merupakan partisi pembeda. Kemudian kardinalitas minimum dari banyaknya partisi disebut dimensi partisi. Dimensi partisi dari masing-masing graf yaitu:

a. Dimensi partisi pada graf sisir $C b_{n}$

b. Dimensi partisi pada graf garis dari graf $\operatorname{sisir} L\left(C b_{n}\right)$

$$
\operatorname{pd}\left(C b_{n}\right)=\left\{\begin{array}{l}
2, \text { untuk } n=2 \\
3, \text { untuk } n \geq 3
\end{array}\right.
$$

$$
\operatorname{pd}\left(L\left(C b_{n}\right)\right)= \begin{cases}2, & \text { untuk } n=2 \\ 3, & \text { untuk } n \geq 3\end{cases}
$$

c. Dimensi partisi pada graf kuadrat dari graf sisir $C b_{n}^{2}$

$$
\operatorname{pd}\left(C b_{n}^{2}\right)= \begin{cases}3, & \text { untuk } n=2,3 \\ 4, & \text { untuk } n \geq 4\end{cases}
$$

\section{DAFTAR PUSTAKA}

[1] Khuller S, Raghavachari B dan Rosenfeld A. Landmark in Graphs. Discrete Applied Mathematics. 1996; 70:217-229.

[2] Munir R. Matematika Diskrit. Ed ke-3. Bandung: Informatika; 2010.

[3] Alfarisi R. Dimensi Partisi dan Dimensi Partisi Bintang Graf Hasil Operasi Comb Dua Graf Terhubung. Institut Teknologi Sepuluh Nopember. Fakultas Matematika dan Ilmu Pengetahuan Alam. Surabaya. 2017 (Tesis).

[4] Esakkiammal E, Deepa B dan Thirusangu K. Some Labeling on Square Graph of Comb. International Journal of Mathematics Trends and Technology (IJMTT). 2018; 27-30.

[5] Roza I, Narwen dan Zulakmal. Graf Garis (Line Graph) dari Graf Siklus, Graf Lengkap, dan Graf Bintang. Jurnal Matematika UNAND. 2014; 3:01-04.

[6] Le VB dan Tuy NN. The Square of a Block Graph. Discrete Mathematics. 2010; 310:734-741.

[7] Riza R. Dimensi Partisi Graf Gir. Jurnal Matematika UNAND. 2016; 1:21-27.

[8] Chartrand G, Salehi E dan Zhang P. The partition Dimension of a Graph. Aequationes Math. 2000; 59:45-54.

ANNISATUL KHAIRIAH : Jurusan Matematika FMIPA Untan, Pontianak, nisakhairiah96@gmail.com

EVI NOVIANI : Jurusan Matematika FMIPA Untan, Pontianak, evi_noviani@math.untan.ac.id

FRANSISKUS FRAN : Jurusan Matematika FMIPA Untan, Pontianak, fransiskusfran@math.untan.ac.id 